\title{
BMJ Open Night work and breast cancer in women: a Swedish cohort study
}

\author{
Torbjörn Åkerstedt, ${ }^{1,2}$ Anders Knutsson, ${ }^{3}$ Jurgita Narusyte, ${ }^{1}$ Pia Svedberg, ${ }^{1}$ \\ Göran Kecklund, ${ }^{2,4}$ Kristina Alexanderson ${ }^{1}$
}

To cite: Åkerstedt T,

Knutsson A, Narusyte J, et al. Night work and breast cancer in women: a Swedish cohort study. BMJ Open 2015;5: e008127. doi:10.1136/ bmjopen-2015-008127

- Prepublication history and additional material for this paper is available online. To view these files please visit the journal online (http://dx.doi.org/10.1136/ bmjopen-2015-008127).

Received 13 March 2015 Accepted 20 March 2015

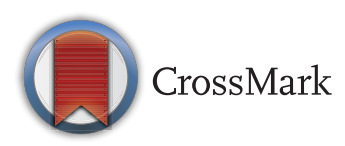

${ }^{1}$ Department of Clinical Neuroscience, Karolinska Institutet, Stockholm, Sweden

${ }^{2}$ Stress Research Institute, Stockholm University, Stockholm, Sweden

${ }^{3}$ Department of Health Sciences, Mid Sweden University, Sundsvall, Sweden

${ }^{4}$ Behavioral Science Institute, Radboud University, Nijmegen, The Netherlands

Correspondence to Dr Torbjörn Åkerstedt; torbjorn.akerstedt@ki.se

\section{ABSTRACT}

Objectives: Recent research has suggested a moderate link between night work and breast cancer in women, mainly through case-control studies, but nonsignificant studies are also common and cohort studies are few. The purpose of the present study was to provide new information from cohort data through investigating the association between the number of years with night work and breast cancer among women.

Design: Cohort study of individuals exposed to night shift work in relation to incidence of breast cancer in women.

Setting: Individuals in the Swedish Twin registry, with follow-up in the Swedish Cancer Registry.

Participants: 13656 women from the Swedish Twin Registry, with 3404 exposed to night work.

Outcome measures: Breast cancer from the Swedish Cancer Registry (463 cases) during a follow-up time of 12 years.

Results: A Cox proportional hazards regression analysis with control for a large number of confounders showed that the HR was HR=1.68 $(95 \%$ $\mathrm{Cl} 0.98$ to 2.88 ) for the group with $>20$ years of night work. When the follow-up time was limited to ages below 60 years, those exposed $>20$ years showed a $\mathrm{HR}=1.77$ (95\% Cl 1.03 to 3.04$)$. Shorter exposure to night work showed no significant effects.

Conclusions: The present results, together with previous work, suggest that night work is associated with an increased risk of breast cancer in women, but only after relatively long-term exposure.

\section{INTRODUCTION}

Within the European Union (27 countries) $18.7 \%$ of the work force work night time (22:00-6:00) at least once per month, according to the European Working Conditions Survey (http:/ /www.eurofound.europa.eu). In 2007, the International Agency for Research on Cancer (IARC) carried out a review of available knowledge on the link between breast cancer in women and shift work, ${ }^{1}$ and concluded that six of the eight studies showed excessive risk for female shift workers with night work to develop breast cancer

\section{Strengths and limitations of this study}

Studies of night work and cancer have seldom used a cohort approach. The major contribution of the present study is that it uses a cohort to demonstrate the link between long-term exposure to shift work and breast cancer in women.

- Another strength is the unique person identification number for all Swedish citizens, which made it possible to obtain high-quality and complete data on cancer incidence during follow-up.

- A weakness of the present study is the reliance on self-reported data, which may make exposure estimates somewhat unreliable.

- Another weakness is the lack of information on the number of night shifts worked.

(ORs=1.3-1.8). This led the IARC to classify shift work in category two on the list of causes of cancer, that is, as a 'probable causative link'. The effect of time of exposure was not clear, but a duration of 20 years was suggested by Kolstad, ${ }^{2}$ who found limited evidence for the relationship between night shifts and breast cancer.

A new review with some added studies came to the same conclusion, ${ }^{3}$ and four new meta analyses appeared in $2013 .^{4-7}$ The first two found relatively strong links, while Ijaz et al argued that the evidence was weak for case-control studies and non-significant for cohort studies (although 1 significant study was left out because of lack of data on duration of exposure). ${ }^{8}$ The meta analysis was criticised for leaving out several relevant studies. ${ }^{9}$ In the meta analysis it was also maintained that case-control studies are less reliable than cohort studies in terms of information on exposure since there is a risk of recall bias. Kamdar et $a l^{7}$ found that the evidence was weak in their meta-analysis and they could not find an effect of duration of exposure for night shifts.

A majority of case-control studies where night work has been determined on an individual level (excluding studies with exposure based only on belonging to certain 
occupations with frequent night shifts) showed significant results for night work and breast cancer, ${ }^{10-14}$ but several did not. ${ }^{15-20}$ For cohort studies, significant associations were observed in three studies, ${ }^{8}{ }^{21} 22$ but not in two other studies. ${ }^{23}{ }^{24}$ Considering the lack of decisive results for cohort studies, it would seem important to obtain further data on night work and breast cancer.

Also, duration of exposure seems important, particularly at levels exceeding 15 years. ${ }^{10-12} 2122$ Most of the nonsignificant studies had a longest duration category starting well below 15 years. However, both studies by Hansen et al showed effects already at $>5$ years of exposure.

The mechanism of the relation between night work and cancer is hypothesised to be influences of light at night on the level of melatonin, as well as disturbances of the circadian rhythm. ${ }^{1}$ It appears that, for example, blind women have a lower risk for breast cancer than sighted women. ${ }^{25}$ Animal studies have shown that human tumours implanted in mice can be manipulated in terms of growth by changing the flow of melatonin. ${ }^{26}{ }^{27}$ High levels of melatonin seem to also protect healthy cells from carcinogenic processes. ${ }^{26} 27$ Phase advancing the light exposure in mice increases the malign progression in tumour cells. ${ }^{28}$ Female rats with implanted human breast cancer tumours show growth when the light intensity is increased and melatonin secretion decreased. Melatonin also suppresses the uptake of fatty acids during the night. ${ }^{27}$

Even if the available studies seem to favour a connection between night work and breast cancer, there remains considerable evidence of the opposite. The cohort studies are few and include two studies of a particular occupational group (nurses ${ }^{21} 22$ ), which could be difficult to generalise to the population of night working women in general. Thus, there seems to be a need for a population study with long duration exposure. The purpose of the present study was to investigate the association between the number of years with night work and breast cancer in a cohort of women.

\section{METHOD}

\section{Design}

The design was a prospective cohort study beginning at the time of responding to the questions. Twins born in Sweden before 1959, who participated in the Screening Across the Lifespan Twin (SALT) study conducted by the Swedish Twin Registry (STR), and who at the time of the interview were 41-60 years old were included. Each individual participated in the SALT computer-assisted telephonic interview once between 1998 and March 2003. The response rate was $74 \%$. The interview included a number of items regarding different diseases and symptoms; the procedure for data collection has previously been described in detail elsewhere. ${ }^{29}$ Data on cancer were obtained from the Swedish Cancer Registry and from the Cause of Death Register, and linked to the twins by using the unique person identification number available for all Swedish citizens. The regional ethical committee approved the study.

\section{Variables}

The exposed group was constituted of those who had worked at night for 1-45 years according to the response to the question: "For how many years have you had working hours that meant that you worked nights at least now and then". This group was compared with a group that had not worked nights. In addition, further categorisation of exposure was based on intervals in multiples of 5 , that is, $1-5,6-10,11-20$ or $21-45$ years, in combination with observations that an effect may be expected for $\geq 30$ years or $\geq 20$ years. However, too few cases were obtained for categorisation at $\geq 30$ years. Breast cancer was defined as having at least one new cancer diagnosis after the date of the interview, either according to the Cancer Register or to the Cause of Death Register.

The following variables were used as covariates:

Educational level $(0=$ compulsory (reference), $1=$ more than compulsory). Tobacco Use $(0=$ no tobacco (reference), 1=tobacco use (includes current or previous regular smoking/taking snuff as well as occasional smoking or use of snuff) ). Alcohol use $(0=$ no alcohol consumption (reference), 1=alcohol consumption). Physical activity $(0=$ moderate exercise (reference), $1=$ low exercise, 2=high exercise). (Question in SALT: "Of these 7 alternatives, which fits your annual exercise pattern?"). Body mass index $\left(0=\right.$ normal weight $\left(>18.5-25 \mathrm{~kg} / \mathrm{m}^{2}\right.$; reference), $1=$ underweight $(\leq 18.5), 3=$ overweight $(>25-30)$, $4=$ obesity $(>30))$. Only one participant was underweight and was eliminated. Have children $(0=$ no children (reference), $1=$ have children). Coffee use ( $1=$ no coffee (reference), $2=1-2$ cups a day, $3=3-4$ cups a day; $4=\geq 5$ cups a day). Previous cancer $(0=$ no cancer (reference), $1=$ have cancer) at the time of interview. Menopause $(0=$ not passed (reference), 1=have passed) at the time of interview. Use of hormones, including oral contraceptives $(0=$ no use (reference), $1=$ use $)$ at the time of interview.

\section{Statistical analysis}

Frequencies were used to describe the background and covariates. The differences between day and night workers were tested by $\chi^{2}$ test for categorical variables and $t$ test for continuous variables. In the analyses of associations, people with missing information on a specific covariate were excluded in the analyses including that covariate. Multiple Cox proportional hazard regression analyses for covariates were used to compute HRs with 95\% CIs. Exposure was defined as night work (or not) with a subdivision for duration of exposure. All individuals contributed with time until day of the first breast cancer diagnosis or censoring. Censoring events included other cancer diagnosis during the follow-up, date of death, or end of follow-up time, whichever came first. The analyses were adjusted for the statistical within-twin pair dependency. 
Table 1 Characteristics of the study population at baseline

\begin{tabular}{|c|c|c|c|}
\hline & \multicolumn{2}{|l|}{ Number of individuals (\%) } & \multirow[b]{2}{*}{ p Value } \\
\hline & Day workers $(n=10252)$ & Night workers $(n=3404)$ & \\
\hline Age, years (SD) & $51.8(4.7)$ & $51.1(4.9)$ & $<0.001$ \\
\hline Education & & & $<0.001$ \\
\hline Compulsory & $3452(34 \%)$ & $855(25 \%)$ & \\
\hline More than compulsory & $6798(66 \%)$ & $2546(75 \%)$ & \\
\hline Children & & & $<0.001$ \\
\hline Have children & $8931(87 \%)$ & $3046(89 \%)$ & \\
\hline Do not have children & $1321(13 \%)$ & $358(11 \%)$ & \\
\hline Tobacco use & & & $<0.001$ \\
\hline No & $2091(21 \%)$ & $554(17 \%)$ & \\
\hline Yes & $7885(79 \%)$ & $2759(83 \%)$ & \\
\hline BMI & & & $<0.001$ \\
\hline Normal weight & $6482(64 \%)$ & $2042(61 \%)$ & \\
\hline Underweight & $205(2 \%)$ & $57(2 \%)$ & \\
\hline Overweight & $2698(27 \%)$ & $956(29 \%)$ & \\
\hline Obesity & 705 (7\%) & $297(9 \%)$ & \\
\hline Physical activity & & & 0.059 \\
\hline Moderate & $2599(25 \%)$ & $844(25 \%)$ & \\
\hline Low & 2487 (24\%) & $769(23 \%)$ & \\
\hline High & $5115(50 \%)$ & $1772(52 \%)$ & \\
\hline Alcohol consumption & & & 0.675 \\
\hline No alcohol & $202(4 \%)$ & $57(4 \%)$ & \\
\hline Alcohol & $4537(96 \%)$ & $1365(96 \%)$ & \\
\hline Did not know/did not answer & $5(0.1)$ & $2(0.1 \%)$ & \\
\hline Coffee consumption & & & $<0.001$ \\
\hline No coffee & $713(7 \%)$ & $223(7 \%)$ & \\
\hline $1-2$ cups a day & $2640(26 \%)$ & $786(23 \%)$ & \\
\hline $3-4$ cups a day & $4144(40 \%)$ & $1234(36 \%)$ & \\
\hline $5+$ cups a day & $2746(27 \%)$ & $1156(34 \%)$ & \\
\hline Passed menopause & $4397(43 \%)$ & $1222(36 \%)$ & $<0.001$ \\
\hline Use of hormones & & & $<0.05$ \\
\hline Yes & $5941(58 \%)$ & $2040(60 \%)$ & \\
\hline No & $4301(42 \%)$ & $1362(40 \%)$ & \\
\hline Previous cancer & & & 0.339 \\
\hline No & $9144(89 \%)$ & $3016(89 \%)$ & \\
\hline Yes & $1108(11 \%)$ & $388(11 \%)$ & \\
\hline New cancer diagnosis during follow-up & & & 0.412 \\
\hline No cancer & $9320(91 \%)$ & $3120(92 \%)$ & \\
\hline Breast & $354(3 \%)$ & $109(3 \%)$ & \\
\hline Other cancer & $578(6 \%)$ & $175(5 \%)$ & \\
\hline Time to breast cancer diagnosis (years (SD)) & $4.8(2.9)$ & $4.4(2.8)$ & 0.190 \\
\hline
\end{tabular}

The follow-up time was stratified into two groups based on the findings of Knutsson et al -group 1: all women aged 59 years old or younger at the interview were followed until they turned 60 years old $(\mathrm{N}=13656)$. Group 2: all women aged 59 years old or younger at the interview were followed until the end of follow-up time, that is, 30 Dec $2010(\mathrm{~N}=13$ 656). All statistical analyses were performed using SAS V.9.4.

\section{RESULTS}

The mean follow-up time was 8.7 years (range 0-13). The total number of person-years in the cohort when participants were censored after death, time of diagnosis, or after 31 December 2010, was 119086. Breast cancer occurred in 463 women between baseline and the last day of the complete follow-up, and 498 women died during follow-up.

Background information is presented in table 1. Night workers were slightly younger, had a longer education, had more children, used more tobacco, were more overweight, drank more coffee, were less likely to have passed their menopause and used hormone therapy less frequently. They did not differ in physical activity, alcohol consumption, previous (before interview) or new cancer, or time to cancer diagnosis (from the time of the interview).

The cumulative incidence of breast cancer was 3.2\% among female night workers and 3.5\% among female 
Table 2 HRs for shift work exposure groups applying multiple Cox analysis for prediction of breast cancer* after baseline among female night workers, and with $95 \%$ Cls

\begin{tabular}{|c|c|c|c|c|}
\hline & $\begin{array}{l}\text { Duration of } \\
\text { exposure, years }\end{array}$ & $\begin{array}{l}\text { Cases/no } \\
\text { cases }\end{array}$ & $\begin{array}{l}\text { Complete follow-up } \\
\text { HR }(95 \% \mathrm{Cl}) \dagger\end{array}$ & $\begin{array}{l}\text { Follow-up to } 60 \text { years } \\
\text { HR }(95 \% \mathrm{CI}) \ddagger\end{array}$ \\
\hline \multicolumn{5}{|l|}{ No night work versus ever night work } \\
\hline No night work & 0 & $354 / 9320$ & 1 & 1 \\
\hline Working nights for: (unadjusted) & $1-45$ & $109 / 3120$ & $0.93(0.75$ to 1.16$)$ & $0.86(0.70$ to 1.07$)$ \\
\hline No night work & 0 & $354 / 9320$ & 1 & 1 \\
\hline Working nights for: (adjusted)§ & $1-45$ & $109 / 3120$ & $0.94(0.73$ to 1.22$)$ & $0.96(0.74$ to 1.24$)$ \\
\hline \multicolumn{5}{|c|}{ No night work versus years of shift work } \\
\hline No night work & 0 & $354 / 9320$ & 1 & 1 \\
\hline \multirow[t]{4}{*}{ Working nights for: (unadjusted) } & $1-5$ & $57 / 1614$ & $0.94(0.71$ to 1.24$)$ & $0.85(0.65$ to 1.13$)$ \\
\hline & $6-10$ & $16 / 623$ & $0.69(0.42$ to 1.14$)$ & $0.63(0.38$ to 1.04$)$ \\
\hline & $11-20$ & $18 / 596$ & $0.81(0.50$ to 1.30$)$ & $0.72(0.45$ to 1.16$)$ \\
\hline & $21-45$ & $18 / 287$ & $1.62(1.01$ to 2.60$)$ & 1.92 (1.19 to 3.08$)$ \\
\hline No night work & 0 & $354 / 9320$ & 1 & 1 \\
\hline \multirow[t]{4}{*}{ Working nights for: (adjusted)§ } & $1-5$ & $57 / 1614$ & $0.92(0.65$ to 1.29$)$ & $0.93(0.66$ to 1.31$)$ \\
\hline & $6-10$ & $16 / 623$ & $0.79(0.45$ to 1.37$)$ & $0.79(0.45$ to 1.38$)$ \\
\hline & $11-20$ & $18 / 596$ & 0.77 (0.43 to 1.38$)$ & $0.80(0.45$ to 1.42$)$ \\
\hline & $21-45$ & $18 / 287$ & 1.68 (0.98 to 2.88$)$ & 1.77 (1.03 to 3.04$)$ \\
\hline \multicolumn{5}{|c|}{$\begin{array}{l}\text { Reference: non-exposed. } \mathrm{N}=13656 \text {, total number of cases }=463 . \\
\text { *No cancer as reference. } \\
\text { †Follow-up until } 31 \text { December } 2010 \text {. } \\
\text { fFollow-up until the age of } 60 \text {. } \\
\text { §Adjusted for: age+education level+tobacco consumption+body mass index+having children+coffee consumption+previous cancer+use of } \\
\text { hormones including oral contraceptives. } \\
\text { Bold typeface indicates significance at } p<0.05 \text {. }\end{array}$} \\
\hline
\end{tabular}

non-night workers $\left(\chi^{2}=0.49, \mathrm{p}=0.48\right)$. Table 2 shows that the proportion was higher in the group with the highest exposure.

Results of the Cox regression analyses, regardless of years of exposure, did not show any significant association to night work (table 2). When broken down into different durations of exposure, a significant HR for the highest exposure group without adjustment for confounders was seen (table 2). This effect was reduced after adjustment for the full group, but remained in the group that was followed up to the age of 60 years.

Alcohol consumption was not entered into the main analysis since the internal loss of data was $>50 \%$ for this variable. However, a separate analysis showed that the values with adjustment for alcohol was $\mathrm{HR}=1.64$ (95\% CI 0.76 to 3.53) for the exposure group with $21-45 \mathrm{~h}$ of night work, with follow-up of up to 60 years, $\mathrm{N}=5870$.

\section{DISCUSSION}

The results showed a significant association between exposure to night work for $>20$ years and breast cancer in women who were followed up to the age of 60 years. For the complete group, independent of exposure duration, there was a trend in the same direction.

Our finding of effects for >20 years of night work exposure on breast cancer agrees with the cohort studies by Schernhammer et $a l^{21}{ }^{22}$ and three of the four casecontrol studies that included results for at least 15 years of exposure to night work. ${ }^{10-12}$ The fourth, nonsignificant, study was that of Pronk et al. ${ }^{23}$ The significant
HRs or ORs for these studies vary from 1.36 to 2.2. Most of the non-significant studies had shorter exposure times. The studies by Hansen and colleagues ${ }^{10}{ }^{11}$ showed significant effects already at $>5$ years of exposure, despite a rather small size (783 nurses with night work, 252 without night work and 310 cases in the first study, and 187 women in the military with night work, 450 without night work and 141 cases in the second study, respectively).

One large (>280 000 participants) recent Dutch study contrasts with the impression of an effect of long-term exposure to night work on breast cancer. ${ }^{30}$ However, the authors of that study point out several critical limitations. One concerns the fact that exposure to night work was defined at baseline as current night work, which does not give information on accumulated exposure, which seems important. Instead, duration of employment was used as a proxy; but it is doubtful to what extent this is a reasonable procedure since the rate of attrition is very high in shift work. In one of our own studies of entry/exit to/ from shift work, for example, it was found that $59 \%$ of the night shift workers had switched to non-night work over a 5-year period. ${ }^{31}$ A second limitation mentioned is that Dutch women have twice as high a rate of part time work as the European average. This means that the number of night shifts worked may be much lower than in comparable studies, which is very likely to reduce likelihood of breast cancer.

The present results were not significant for the whole group, although there was a strong trend, but only for the group followed up until the age of 60. Also, 
Knutsson et $a l^{8}$ found somewhat stronger results when follow-up was restricted to 60 years of age. One might assume that including the years after 60 years of age may add many other causes of breast cancer, possibly hiding the effect of night work. Knutsson et al did not analyse effects of duration of exposure. Our study may have suffered from the high baseline age of 40-60 years, compared with other studies using the whole adult age range. This may have attenuated the association between night work and breast cancer. Apart from the high baseline age, the present study also has several other limitations, which are shared with most other epidemiological studies. One such limitation is the reliance on selfreported exposure data, which is likely to produce unreliable estimates due to recall bias and to the respondents' interpretation of the meaning of 'worked nights'. It is not clear if individuals with very late afternoon shifts or very early night shifts may have considered those shifts as night work. If present, the inclusion of such participants would, likely, have attenuated night work effects. Clearly, objective data on exposure are needed in future studies. Another limitation is the lack of information on the exposure to light at night. Consequently, we cannot test whether light at night, suppression of melatonin or circadian disruption explain the increased risk for the group with long (+20 years) exposure for night work. It should also be pointed out that the day workers included shift workers not working night shifts.

A strength of this study is the longitudinal cohort design. The exposure to night work came before the disease. The unique person identification number for all Swedish citizens made it possible to obtain highquality and complete data from the Swedish cancer registry on cancer incidence during follow-up. Another advantage is that we had access to information on several potential confounding factors that we could take into account in the analyses.

Most of the assumed confounders of the night work -breast cancer link were included in the analysis. One exception is alcohol consumption, since this variable caused a loss of cases by $>50 \%$. However, this probably does not explain the outcome, since night workers had a lower consumption of alcohol than day workers. The HR with alcohol included as a covariate (and with only 4744 participants remaining) was relatively close to the value obtained with alcohol excluded, but the CI was wider, presumably due to the loss of participants, hence power was lost. Another factor that was not tested in the present study is the importance of genetic predisposition for the association. Whether genetic factors may explain the association between night work and breast cancer could be tested by studying identical (monozygotic) twins where one twin in a pair was a night worker while the other was not (ie, twins discordant for night work). However, there were too few pairs of discordant monozygotic twin pairs in the present study to permit such an analysis. A third factor is the use of a twin setting, even though the analyses were corrected for this factor. Critics sometimes argue that results from twin studies do not apply to the general population because twins differ from singletons in several aspects. When it comes to shift work and cancer incidence, the results of the present study are equal to results obtained in studies using singletons, hence we have no reason to believe our results would not be generalisable.

We tested potential confounding by using measures of use of hormones inclusive of contraceptive pills, obesity, having children, smoking and educational level. Yet, even if many potential confounders have been adjusted for, there may still be others not considered in the present study. Among them may be age of first exposure to shift work. For example, work shifts at a young age increased the risk of multiple sclerosis, a finding that could indicate that certain individuals are prone to develop disease early when exposed to shift work. ${ }^{32}$

Taken together, the present results add to the impression that night work contributes to breast cancer in women, at least in groups with long exposure ( $>20$ years). Short-term exposure seems to have no links to breast cancer in women.

Contributors TÅ initiated and designed the study, discussed the analyses and wrote the manuscript. JN analysed the data and commented on the manuscript. PS carried out a second independent analysis to ensure that the results were solid. She also discussed the results and commented on the manuscript. KA supervised and participated in the planning of the analyses and commented on the manuscript. AK and GK commented on the results and the manuscript.

Funding This study was funded by the AFA Insurance Company (grant number 120264).

Competing interests None declared.

Ethics approval The ethical committee for the Stockholm Region.

Provenance and peer review Not commissioned; externally peer reviewed.

Data sharing statement The data cannot be made publically available. According to the Swedish Ethical Review Act, the Personal Data Act, and the Administrative Procedure Act, data can only be made available, after legal review, for researchers who meet the criteria for access to this type of sensitive and confidential data. Readers may contact professor Kristina Alexanderson (kristina.alexanderson@ki.se) regarding the data.

Open Access This is an Open Access article distributed in accordance with the Creative Commons Attribution Non Commercial (CC BY-NC 4.0) license, which permits others to distribute, remix, adapt, build upon this work noncommercially, and license their derivative works on different terms, provided the original work is properly cited and the use is non-commercial. See: http:// creativecommons.org/licenses/by-nc/4.0/

\section{REFERENCES}

1. Stevens RG. Testing the light-at-night (LAN) theory for breast cancer causation. Chronobiol Int 2011;28:653-6.

2. Kolstad HA. Nightshift work and risk of breast cancer and other cancers-a critical review of the epidemiologic evidence. Scand $J$ Work Environ Health 2008;34:5-22.

3. Bonde JP, Hansen J, Kolstad HA, et al. Work at night and breast cancer-report on evidence-based options for preventive actions. Scand J Work Environ Health 2012;38:380-90. 
4. Jia YJ, Lu YS, Wu KJ, et al. Does night work increase the risk of breast cancer? A systematic review and meta-analysis of epidemiological studies. Cancer Epidemiol 2013;37:197-206.

5. Wang F, Yeung KL, Chan WC, et al. A meta-analysis on dose-response relationship between night shift work and the risk of breast cancer. Ann Oncol 2013;24:2724-32.

6. ljaz S, Verbeek J, Seidler A, et al. Night-shift work and breast cancer-a systematic review and meta-analysis. Scand J Work Environ Health 2013;39:431-47.

7. Kamdar BB, Tergas Al, Mateen FJ, et al. Night-shift work and risk of breast cancer: a systematic review and meta-analysis. Breast Cancer Res Treat 2013;138:291-301.

8. Knutsson A, Alfredsson L, Karlsson B, et al. Breast cancer among shift workers: results of the WOLF longitudinal cohort study. Scand $J$ Work Environ Health 2013;39:170-7.

9. Stevens R, Hansen J, Schernhammer E, et al. Response to letter to the editor, re: ljaz S, et al. "Night-shift work and breast cancer-a systematic review and meta-analysis". Scand J Work Environ Health 2013;39:631-2

10. Hansen J, Lassen CF. Nested case-control study of night shift work and breast cancer risk among women in the Danish military. Occup Environ Med 2012;69:551-6.

11. Hansen J, Stevens RG. Case-control study of shift-work and breast cancer risk in Danish nurses: impact of shift systems. Eur J Cancer 2012;48:1722-9.

12. Lie JA, Roessink J, Kjaerheim K. Breast cancer and night work among Norwegian nurses. Cancer Causes Control 2006;17:39-44.

13. Grundy A, Richardson H, Burstyn I, et al. Increased risk of breast cancer associated with long-term shift work in Canada. Occup Environ Med 2013;70:831-8.

14. Davis S, Mirick DK, Stevens RG. Night shift work, light at night, and risk of breast cancer. J Natl Cancer Inst 2001;92:1557-62.

15. Lie JA, Kjuus $\mathrm{H}$, Zienolddiny $\mathrm{S}$, et al. Night work and breast cancer risk among Norwegian nurses: assessment by different exposure metrics. Am J Epidemiol 2011;173:1272-9.

16. Menegaux F, Truong T, Anger A, et al. Night work and breast cancer: a population-based case-control study in France (the CECILE study). Int J Cancer 2013;132:924-31.

17. O'Leary ES, Schoenfeld ER, Stevens RG, et al. Shift work, light at night, and breast cancer on Long Island, New York. Am J Epidemiol 2006;164:358-66.
18. Pesch B, Harth V, Rabstein S, et al. Night work and breast cancerresults from the German GENICA study. Scand J Work Environ Health 2010;36:134-41.

19. Li W. Magnetic fields, night-shift work and the risk of breast cancer among female textile workers in Changhai, China. Washington: University of Washington, 2011.

20. Fritschi L, Erren TC, Glass DC, et al. The association between different night shiftwork factors and breast cancer: a case-control study. Br J Cancer 2013;109:2472-80.

21. Schernhammer ES, Kroenke CH, Laden F, et al. Night work and risk of breast cancer. Epidemiology 2006;17:108-11.

22. Schernhammer ES, Laden F, Speizer FE, et al. Rotating night shifts and risk of breast cancer in women participating in the nurses' health study. J Natl Cancer Inst 2001;93:1563-8.

23. Pronk A, Ji BT, Shu XO, et al. Night-shift work and breast cancer risk in a cohort of Chinese women. Am J Epidemiol 2010;171:953-9.

24. Tynes T, Hannevik M, Andersen A, et al. Incidence of breast cancer in Norwegian female radio and telegraph operators. Cancer Causes Control 1996;7:197-204.

25. Flynn-Evans EE, Stevens RG, Tabandeh H, et al. Total visual blindness is protective against breast cancer. Cancer Causes Control 2009;20:1753-6.

26. Blask DE. Melatonin, sleep disturbance and cancer risk. Sleep Med Rev 2009;13:257-64.

27. Blask DE, Hill SM, Dauchy RT, et al. Circadian regulation of molecular, dietary, and metabolic signaling mechanisms of human breast cancer growth by the nocturnal melatonin signal and the consequences of its disruption by light at night. J Pineal Res 2011;51:259-69.

28. Filipski E, Delaunay F, King VM, et al. Effects of chronic jet lag on tumor progression in mice. Cancer Res 2004;64:7879-85.

29. Lichtenstein P, Defaire U, Floderus B et al. The Swedish Twin Registry: a unique resource for clinical, epidemiological and genetic studies. J Intern Med 2002;252:184-205.

30. Koppes LL, Geuskens GA, Pronk A, et al. Night work and breast cancer risk in a general population prospective cohort study in The Netherlands. Eur J Epidemiol 2014;29:577-84.

31. Akerstedt T, Nordin M, Alfredsson L, et al. Sleep and sleepiness: impact of entering or leaving shiftwork - a prospective study. Chronobiol Int 2010;27:987-96.

32. Hedstrom AK, Akerstedt T, Hillert J, et al. Shift work at young age is associated with increased risk for multiple sclerosis. Ann Neurol 2011;70:733-41. 